\title{
Modeling workability of asphalt concrete performance at different temperatures using a statistical model
}

\author{
Ahmad Kamil Arshad, Md Diah J and Salah Mohamed Khalil* \\ Faculty of Civil Engineering Universiti Teknologi MARA UiTM, Shah Alam, Malaysia \\ *Corresponding authorE-mail: khal_salah@yahoo.com
}

\begin{abstract}
In this study, a workability model is used to predict the values of Torque in relation to mix and compaction by Temperature, Gyration, Resilient Modulus, Stability and Flow. The data are obtained from workability-measuring devices developed by the authors. The value of R2 implies that about $95 \%$ variation in the values of Torque can be explained by the variation in mixing and compaction according to Temperature, Gyration, and Resilient Modulus. The regression model as a whole shows that while the value of Torque is largely influenced by Compaction, Mixing Temperature and Gyration; Resilient Modulus, Stability and Flow are not significant determinants of workability. The paper recommends that the effect of workability on the performance of Asphalt concrete should be taken very seriously during the design.
\end{abstract}

Keywords: Hot mix asphalt; Torque; Workability Model; Sensitivity analysis.

\section{Introduction}

Increasing traffic volumes in recent time has resulted in more pressure on roads and has placed more pressure on engineered roads. Technically, a well-designed and constructed road will not only support regional and national developments of a country, but also assist in sustaining the life span of the infrastructure. To achieve this, an adequate mix design is essential. Additionally, the pavement industry has stressed on the importance of achieving reliable and accurate measurement of the workability values in an efficient and convenient manner. In the meantime, the demand for durable and quality products has resulted in the need for improvement in research relating to the workability of Hot Mix. Literature search has suggested that little attention has been directed towards the influence of the mixing temperature on the workability value of the HMA [1, $2 \& 3$ ]. While few previous researches have focused on measuring the workability of the HMA, a number of scholars have evaluated the workability of asphalt concrete by torque or a number of indicators obtained from the gyration compactor and porosity. Although some scholars measure workability by torque $[4,5 \& 6]$, others evaluate workability by some indicators from the gyration compactor and porosity $[1,7,8$, $9 \& 10]$. Measuring workability by a number of indicators from the gyration compactor and porosity to produce the desirable pavement could be achieved by developing an asphalt concrete mixer which uses an electric transducer, at the same time it measures the workability value by means of torque within a period of time. In this study, the theory of mixing is considered as a theoretical and underpinning theory. This paper extends the work of Khalil, et al. [11] who developed a workability measuring device which uses a transducer to capture the values of torque.

\section{Objective}

The main objective of this study is to develop a workability model for evaluating mixing and compaction temperatures, Gyration, Resilient Modulus, Stability and Flow using statistical analyses in relation to the value of Torque. This study extends earlier work on developing workability measuring devices which rely on the accuracy, reliability and efficiency. Thus, this paper focuses on establishing a statistical relationship between the torque (as the dependent variable) and mixing temperature, compaction temperature, gyration, resilient modulus, stability and flow using both the regression and sensitivity analyses (as independent variables). 


\section{Materials and experimental procedure}

\subsection{Materials}

Aggregates used in this study were sourced locally from the Kajang Rock Quarry in the state of Selangor, Malaysia. Three gradations of granite aggregate were selected based on the Malaysian Public Works Department [12] and Malaysian Specification AC14, namely the highest point, midpoint and lowest point of percentage by passing; all of which were used to produce hot asphalt concrete with specific gravity of 2.606, 2.607 and 2.608 gm/cm3 respectively. There are some reasons for the closeness of the values for specific gravity. First of all, the total percentage of the combined aggregates (coarse and fine) is $100 \%$. Secondly, the proportion of coarse and fine aggregates between upper, centre and lower limits is the same, which is shown in Table 1.

Table 1: Proportion of Coarse and fine Aggregates

\begin{tabular}{llll}
\hline Aggregate combination & Highest point \% & Midpoint \% & Lowest point \% \\
\hline Coarse & 46 & 53 & 60 \\
Fine & 53 & 47 & 40 \\
\hline
\end{tabular}

The combined aggregates include coarse aggregates, fine aggregates and mineral filler according to the PWD requirements. This study complies with section 4.3.3.2 (b) of the PWD Malaysia [12], the standard specification for road works on flexible pavements and mineral filler used for the asphalt pavement. The hydrated lime has been used extensively as the mineral filler in HMA mixtures for many years in Malaysia, because of its ability to maintain a good adhesion between the aggregate and the asphalt cement. The Portland cement was used as filler as its effectiveness was tested in this study.

All samples produced are the combination of the aggregates proportioned with bitumen of 80/100 penetrations, having specific gravity of $1.03 \mathrm{gm} / \mathrm{cm} 3$, respectively. The basic properties of the aggregates and bitumen are within the specification in accordance with PWD requirements, as shown in Tables 2 and 3.

\begin{tabular}{|c|c|c|c|}
\hline Property & Test Result & PWD Requirements & Designation \\
\hline Aggregate Abrasion Value AIV \% & 22.6 & $<25 \%$ & ASTM : C 131-96 \\
\hline Aggregate Impact Value, AIV \% & 21.64 & $<25 \%$ & BS 812: PART 112:1990 \\
\hline Aggregate Crushing Value, ACV & 22.5 & $<25 \%$ & BS 812: PART 110 \\
\hline Water absorption \% & 0.65 & $<2 \%$ & ( BS 812 : PART107:1995) \\
\hline $\begin{array}{l}\text { Specific } \\
\text { gm } / \mathrm{cm}^{3}\end{array}$ Gravity each grading & 2.6062 .6072 .608 & & ( BS 812 : PART 107:1995) \\
\hline Flakiness Index \% & 13 & $<25 \%$ & ( BS 812 : PART 105: 1990) \\
\hline Polish Stone Value, PSV & 48 & $>40 \%$ & ( BS 812 : PART 114: 1989) \\
\hline
\end{tabular}

Source: BS British Standard [13, 14 \& 15]; ASTM [16]

Table 3: Basic Properties of Bitumen, RAP and Viscosity

\begin{tabular}{lll}
\hline Type of test & Test result 80/100 & Designation \\
\hline Penetration at $\mathbf{2 5}^{\circ} \mathbf{C}, \mathbf{1 0 0 g}$ & 91 & ASTM D 5 \\
Softening point $\left({ }^{\circ} \mathbf{C}\right)$ & 47.5 & ASTM D 36 \\
Ductility at $\mathbf{2 5}^{\circ} \mathbf{C}(\mathbf{c m})$ & 100 & ASTM D 113 \\
Viscosity at $\mathbf{1 3 5}{ }^{\circ} \mathbf{C}(\mathbf{c P})$ & 425 & ASTM D 4402-02 \\
\hline
\end{tabular}

\subsection{Method}

Asphalt mixtures were prepared in accordance Malaysian standard. The preparation was performed, according to the following procedure. Three types of mix were designed using the AC14 gradation of three different aggregate fractions. Mix designs were the typical dense-graded asphalt concrete using bitumen of 80/100 penetration. The mixtures were identified as mixtures 1, 2 and 3 as shown in Table 4. In this research, 80-100 penetration grades had been used because these are specifically outlined in section 4.11 of the Malaysian standard. 
Table 4: Blended Mix of Asphaltic concrete

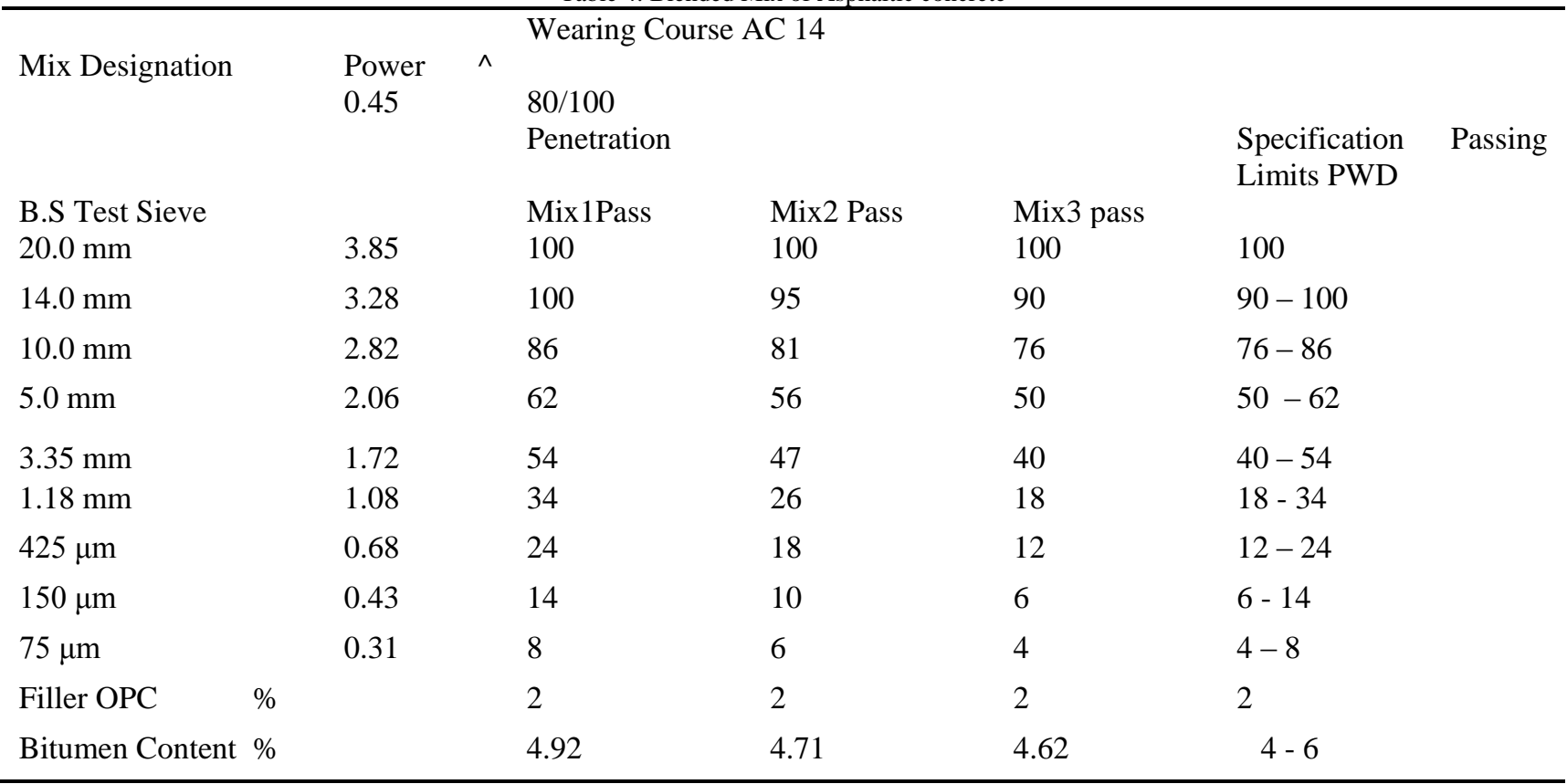

The compactability of the designed asphalt mixtures was evaluated using results from the Superpave gyratory compactor (SGC). The compactability of HMA mixtures is often used to describe how easy or difficult it is to compact a mixture on a roadway. Compaction was achieved by the application of a vertical stress 600 via the end platens to a known mass of asphaltic mixture within a $100 \mathrm{~mm}$ internal $\varnothing$ mould, with the angle of $1.25^{\circ}$. The first stage of the experiment involves the preparation of three mixes labeled mix 1, 2 and 3 as shown in table 3 above. In the first step, mixture 1 was mixed at $140{ }^{\circ} \mathrm{C}$. The temperature was regulated to $135^{\circ} \mathrm{C}$ and mixed again; simultaneously, the torque at this temperature was recorded. The mix was compacted at the same $135{ }^{\circ} \mathrm{C}$ to reach air voids 4 and density, shear stress and gyrations were recorded, and the performance test of Resilient Modulus ASTM 4123, Marshall Stability ASTM D 1559) were conducted. The temperature of the same mix 1 was noted at $140{ }^{\circ} \mathrm{C}$ and regulated to $120{ }^{\circ} \mathrm{C}$. The torque was recorded and later compacted at the same $120^{\circ} \mathrm{C}$ to reach air voids 4 , and density, shear stress and gyrations were recorded, and the performance test Resilient Modulus ASTM 4123, Marshall Stability ASTM D 1559 were again, conducted. The temperature of the same mix 1 was set at $140{ }^{\circ} \mathrm{C}$. The temperature was regulated to the compaction temperature of $105{ }^{\circ} \mathrm{C}$ and $90^{\circ} \mathrm{C}$ and the same procedure was conducted. The second step involves mixing mix 1 at 155 ${ }^{\circ} \mathrm{C}$ and, the temperature was regulated to the compaction temperature of $150 \mathrm{C}$. The torque was recorded and then compacted at this temperature until it reached air voids by 4 percent. Simultaneously, the density, shear stress and gyrations were recorded and the performance tests of Resilient Modulus ASTM 4123, Marshall Stability ASTM D 1559) were carried out. This process was repeated at the compaction temperatures of $135^{\circ} \mathrm{C}, 120^{\circ} \mathrm{C}, 105^{\circ} \mathrm{C}$ and $90{ }^{\circ} \mathrm{C}$, and the density, shear stress and gyrations were recorded and the performance tests Resilient Modulus ASTM 4123, Marshall Stability ASTM D 1559 were carried out. Step one and two were repeated for mix 2 and mix 3, respectively. Also, the total weight of each sample was 3600 grams. The data recorded for each sample lasted 300 seconds in the period of mixing.

\section{Method of analyses}

Prior to the main analysis, normality tests were conducted in order to check the outliers that could negatively influence the findings. The regression analysis was performed to produce a statistical model for the workability value. Finally, a sensitivity analysis was performed to examine the relationship between the torque and compaction temperature.

\subsection{Model development}

Following Soper's [17] statistical guide on his sample, 54 subjects are adequate for this study at 95 percent confidence level. Outliers were removed from the dataset to provide the condition of skewness and kurtosis- the skewness for a normal distribution is zero, and any symmetric data should have skewness near zero. Two normality tests using 
Anderson darling and Kolmogorov Smirnov had been performed. Both tests yielded a normal distribution as shown in Figures 1 and 2 below.

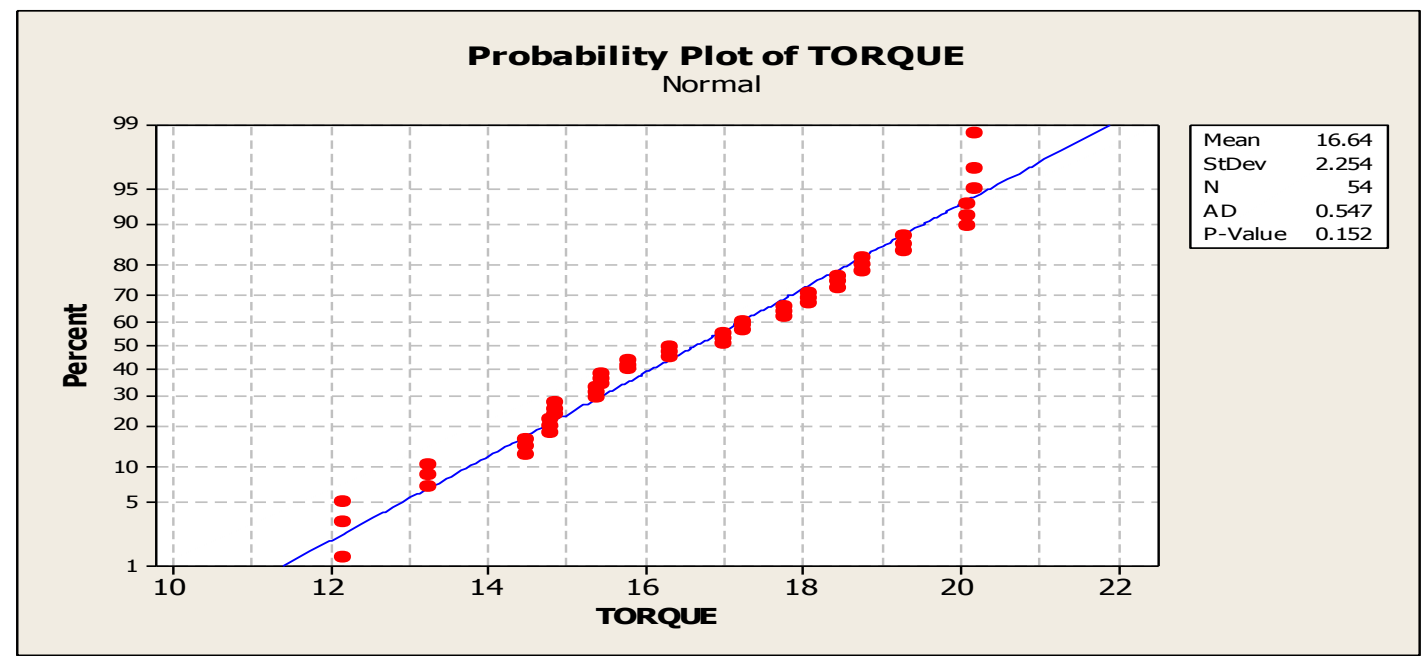

Figure 1: Anderson Darling normality graph

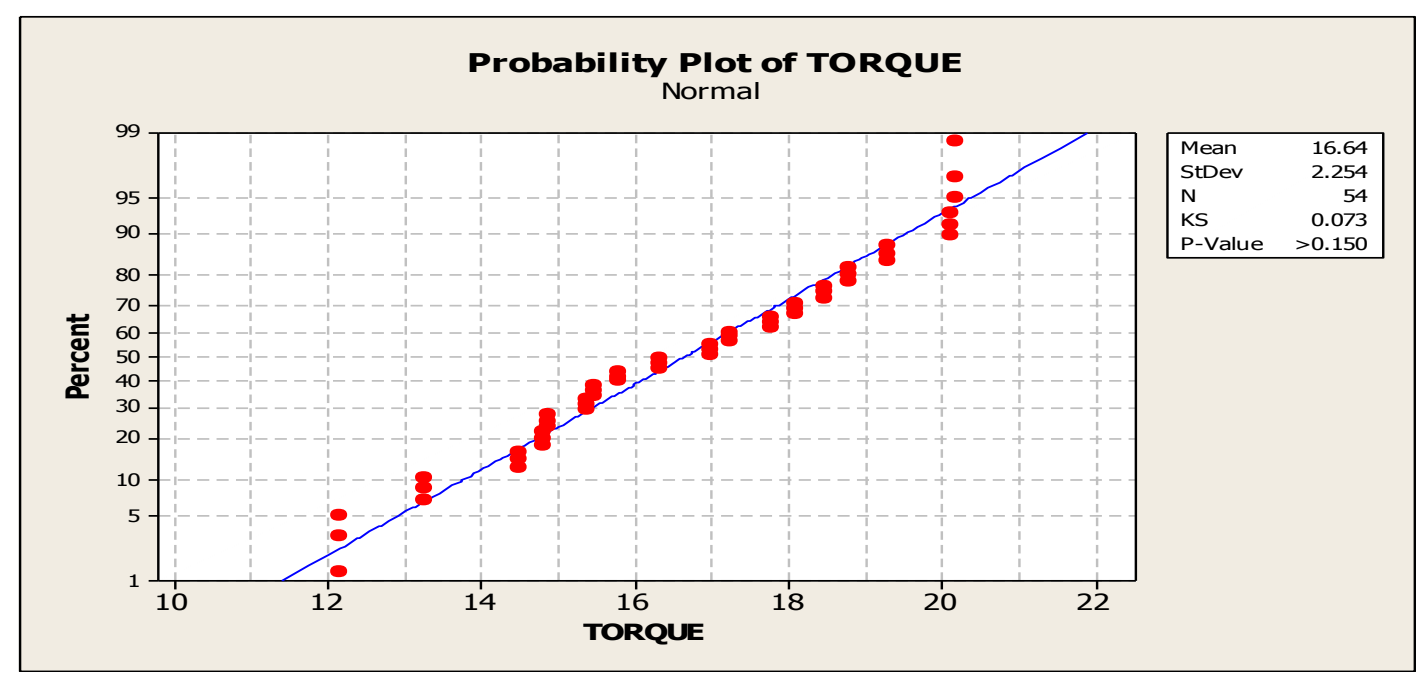

Figure 2: Kolmogorov Smirnov normality graph

\subsection{Sensitivity analysis}

The sensitivity analysis provides a general qualitative understanding of the trends of the material behaviour in relation to the variation in parameters. The purpose of a sensitivity analysis is to correlate various features of the output of the mathematical model to the different input factors and parameters of the model. The following are the controlled experiments performed for this sensitivity analysis

- Test A: varying the mixing temperature (MT) parameter, and the other five parameters namely compaction temperature (CT), gyration (G), resilient modulus (RM), stability (St) and flow (F) are fixed under five cases.

- Test B: varying the compaction temperature (MT) parameter, and the other five parameters namely mixing temperature $(\mathrm{CT})$, gyration $(\mathrm{G})$, resilient modulus $(\mathrm{RM})$, stability $(\mathrm{St})$ and flow $(\mathrm{F})$ are fixed under five cases.

- Test $\mathrm{C}$ : varying the gyration $(\mathrm{G})$ parameter and the other five parameters namely mixing temperature (CT), compaction temperatures (MT), resilient modulus (RM), stability (St) and flow (F) are fixed under five cases.

- Test D: varying the Resilient Modulus (RM) parameter and the other five parameters namely mixing temperature (CT), compaction temperatures (MT), gyration $(\mathrm{G})$, stability $(\mathrm{St})$ and flow $(\mathrm{F})$ are fixed under five cases.

- $\quad$ Test E: varying the stability (St) parameter and the other five parameters namely mixing temperature (CT), compaction temperatures (MT), gyration (G), Resilient Modulus (RM) and flow (F) are fixed under five cases. 
- Test F: varying the flow (F) parameter, and the other five parameters namely mixing temperature (CT), compaction temperatures (MT), gyration (G), Resilient Modulus (RM) and stability (St) are fixed under five cases.

\section{Result and discussion}

\subsection{Regression analyses}

Table 5 presents the result of the regression analyses between the variables to determine if there is any significant relationship among them. The results show that Torque has a significant relationship with the mixing temperature, compaction temperature, stability and flow. Stability has a significant relationship with the compaction temperature and Gyration. Furthermore, Gyration and Flow are significantly related. It is on this basis that Torque (a dependent variable) was regressed against the independent variables (Mixing and compaction temperature, Gyration, Resilient Modulus and Flow).

Table 5: Summary of Regression Analysis among variables

\begin{tabular}{|c|c|c|c|c|}
\hline NO & Regression analysis & Regression equation & R-sq & p-value \\
\hline 1 & $\begin{array}{l}\text { Mixing temperature versus compaction } \\
\text { temperature }\end{array}$ & $\begin{array}{l}\text { mixing temperature }=140.0+0.07143 \\
\text { compaction temperature }\end{array}$ & $3.6 \%$ & 0.171 \\
\hline 2 & Mixing temperature versus torque & mixing temperature $=164.8-0.9921$ torque & $8.8 \%$ & $0.029 * *$ \\
\hline 3 & mixing temperature versus gyration & $\begin{array}{l}\text { mixing temperature }=148.9-0.002318 \\
\text { gyration }\end{array}$ & $0.3 \%$ & 0.682 \\
\hline 4 & $\begin{array}{l}\text { Mixing temperature versus resilient } \\
\text { modulus }\end{array}$ & $\begin{array}{l}\text { mixing temperature }=141.7+0.002596 \\
\text { resilient modulus }\end{array}$ & $1.8 \%$ & 0.332 \\
\hline 5 & Mixing temperature versus stability & $\begin{array}{l}\text { mixing temperature }=153.1-0.4768 \\
\text { stability }\end{array}$ & $0.7 \%$ & 0.555 \\
\hline 6 & Mixing temperature versus flow & mixing temperature $=150.2-0.426$ flow & $0.1 \%$ & 0.858 \\
\hline 7 & Compaction temperature versus Torque & $\begin{array}{l}\text { compaction temperature }=248.4-7.917 \\
\text { torque }\end{array}$ & $80.4 \%$ & $0.000^{* *}$ \\
\hline 8 & Compaction temperature versus gyration & $\begin{array}{l}\text { compaction temperature }=120.2-0.01392 \\
\text { gyration }\end{array}$ & $1.7 \%$ & 0.350 \\
\hline 9 & $\begin{array}{l}\text { Compaction temperature versus resilient } \\
\text { modulus }\end{array}$ & $\begin{array}{l}\text { compaction temperature } \\
0.002831 \text { resilient modulus }\end{array}$ & $0.3 \%$ & 0.690 \\
\hline 10 & Compaction temperature versus Stability & $\begin{array}{l}\text { compaction temperature }=47.32+6.870 \\
\text { stability }\end{array}$ & $20.0 \%$ & $0.001 * *$ \\
\hline 11 & Compaction temperature versus flow & $\begin{array}{l}\text { compaction temperature }=141.1-5.529 \\
\text { flow }\end{array}$ & $1.5 \%$ & 0.379 \\
\hline 12 & Torque versus gyration & torque $=17.34-0.002761$ gyration & $5.1 \%$ & 0.099 \\
\hline 13 & Torque versus resilient modulus & torque $=18.14-0.000591$ resilient modulus & $1.0 \%$ & 0.462 \\
\hline 14 & Torque versus stability & torque $=22.68-0.5991$ stability & $11.8 \%$ & $0.011^{* *}$ \\
\hline 15 & Torque versus flow & torque $=8.941+1.740$ flow & $11.5 \%$ & $0.012 * *$ \\
\hline 16 & Gyration versus resilient modulus & $\begin{array}{l}\text { gyration } \\
\text { modulus }\end{array} 157.8+0.03859$ resilient & $0.7 \%$ & 0.559 \\
\hline 17 & Gyration versus stability & gyration $=654.2-39.44$ stability & $7.6 \%$ & $0.044 * *$ \\
\hline 18 & Gyration versus flow & gyration $=1373-252.5$ flow & $35.9 \%$ & $0.000 * *$ \\
\hline 19 & Resilient modulus versus s & resilient modulus $=2487+5.95$ stability & $0.0 \%$ & 0.887 \\
\hline 20 & Resilient modulus versus flow & resilient modulus $=3585-234.6$ flow & $7.0 \%$ & 0.053 \\
\hline 21 & Stability versus flow & stability $=6.645+0.7799$ flow & $7.0 \%$ & 0.053 \\
\hline
\end{tabular}

Table 6 below presents the output of the regression model. The $\mathrm{R}^{2}$ is $94 \%$, which implies that independent variables can explain $94 \%$ changes in the value of the Torque. Hence there is statistical evidence that the independent variables (Mixing and compaction temperature, Gyration, Resilient Modulus and Flow) can be used to predict the values of the torque. The result of the analysis of variance (ANOVA) in table 7 proves that the model is statistically significant, which implies that the model is fit. The regression equation obtained is presented below.

Torque $=36.4-0.0473$ Mixing temperature -0.0989 Compaction temperature -0.00417

Gyration + 0.000050 Resilient Modulus - 0.128 Stability + 0.231 Flow 


\begin{tabular}{lllll}
\multicolumn{5}{c}{ Table 6: Regression Model } \\
\hline Predictor & Coef & SE Coef & T & P \\
Constant & 36.403 & 2.079 & 17.51 & 0.000 \\
Mixing temperature & -0.04730 & 0.01056 & -4.48 & 0.000 \\
Compaction temperature & -0.098894 & 0.004671 & -21.17 & 0.000 \\
Gyration & -0.0041747 & 0.0005287 & -7.90 & 0.000 \\
Resilient modulus & 0.0000502 & 0.0002048 & 0.24 & 0.808 \\
Stability & -0.12794 & 0.07186 & -1.78 & 0.081 \\
Flow & 0.2306 & 0.2401 & 0.96 & 0.342 \\
R-Sq $=94.7 \%$ & & & & \\
\hline
\end{tabular}

Table 7: Analysis of Variance

\begin{tabular}{lcllll}
\hline Source & DF & SS & MS & F & P \\
Regression & 6 & 255.132 & 42.522 & 141.10 & 0.000 \\
Residual Error & 47 & 14.163 & 0.301 & & \\
Total & 53 & 269.295 & & & \\
\hline
\end{tabular}

\subsection{Model validation}

Twenty seven samples (27) were used to validate the model developed. The validation of model is essential because literature has shown that the value $\mathrm{R}^{2}$ is not enough to establish a model, as it requires validation. In this research, the Paired T-Test was performed to validate the model. Statistics literature has demonstrated that model validation is possibly the most important step in the model-building sequence although it is also one of the most overlooked. In addition, a high R2 value does not guarantee that the model fits the data well. The use of a model that does not fit the data well cannot provide good answers to the underlying engineering [18]. The summary of the model validation is presented below. The paired T-test was performed to compare the values of Torque from the model output and laboratory experiments.

Table 8: Paired T test for New TORQUE - TORQUE

\begin{tabular}{lllll}
\hline & N & Mean & StDev & SE Mean \\
\hline new TORQUE & 27 & 16.7109 & 1.6296 & 0.3136 \\
TORQUE & 27 & 15.7087 & 1.9019 & 0.3660 \\
Difference & 27 & 1.00226 & 0.48239 & 0.09284 \\
\hline
\end{tabular}

95\% CI for mean difference: $(0.81143,1.19308)$

T-Test of mean difference $=0($ vs not $=0):$ T-Value $=10.80 \mathrm{P}-$ Value $=0.000$

\subsection{Sensitivity analyses}

Table 9 below presents the summary of the sensitivity analysis consisting of six group tests of the controlled experiment. Test A, to begin, consists of three conditions: minimum, average and maximum values. The mixing temperature was varied from $140^{\circ} \mathrm{C}-155^{\circ} \mathrm{C}$, while the compaction temperature was fixed at 90 for minimum, 115 for average and 150 for maximum value. Gyration was fixed at 35 for minimum, 250 for average and 500 for maximum value. Resilient Modulus was fixed at 1900 for minimum, 2500 for average and 2600 for maximum value. Stability was fixed at 7 for minimum, 10 for average and 15 for maximum value. Flow was fixed at 3 for minimum, 4 for average and 5 for maximum value. In test B, the compacting temperature varies from 90-150 while other variables were fixed at minimum, average and maximum value. Gyration varied from 35-500. Resilient Modulus varied in test D, Stability in test $\mathrm{E}$ and Flow in test $\mathrm{F}$, as shown below. 
Table 9: Summary of the sensitivity analysis

\begin{tabular}{|c|c|c|c|c|c|c|c|c|}
\hline \multicolumn{2}{|c|}{ Model: } & \multicolumn{7}{|c|}{ TORQUE $=36.4-0.0473 \mathrm{MT}-0.0989 \mathrm{CT}-0.00417 \mathrm{G}+0.000050 \mathrm{RM}-0.128 \mathrm{St}+0.231 \mathrm{~F}$} \\
\hline Test & Condition & MT & CT & $\mathrm{G}$ & RM & & $\mathrm{St}$ & $\bar{F}$ \\
\hline \multirow{4}{*}{ A } & & & Fixed at: 90 & Fixed at: 35 & Fixed & at: & Fixed at: 7 & Fixed at: 3 \\
\hline & & Value & & & 1900 & & & \\
\hline & 2 & $\begin{array}{l}\text { increased } \\
{[140 \text { to } 155]}\end{array}$ & Fixed at: 115 & Fixed at: 250 & $\begin{array}{l}\text { Fixed } \\
2500\end{array}$ & at: & Fixed at: 10 & Fixed at: 4 \\
\hline & 3 & & Fixed at: 150 & Fixed at: 500 & $\begin{array}{l}\text { Fixed } \\
2600\end{array}$ & at: & Fixed at: 15 & Fixed at: 5 \\
\hline \multirow[t]{4}{*}{ B } & 1 & Fixed at: 140 & & Fixed at: 35 & $\begin{array}{l}\text { Fixed } \\
1900\end{array}$ & at: & Fixed at: 7 & Fixed at: 3 \\
\hline & 2 & Fixed at: 150 & $\begin{array}{l}\text { increased } \\
{[90 \text { to } 150]}\end{array}$ & Fixed at: 250 & $\begin{array}{l}\text { Fixed } \\
2500\end{array}$ & at: & Fixed at: 10 & Fixed at: 4 \\
\hline & 3 & Fixed at: 155 & & Fixed at: 500 & $\begin{array}{l}\text { Fixed } \\
2600\end{array}$ & at: & Fixed at: 15 & Fixed at: 5 \\
\hline & 1 & Fixed at: 140 & Fixed at: 90 & & Fixed & at: & Fixed at: 7 & Fixed at: 3 \\
\hline \multirow{3}{*}{ C } & 2 & Fixed at: 150 & Fixed at: 115 & $\begin{array}{l}\text { Value } \\
\text { increased } \\
\text { [ } 35 \text { to } 500 \text { ] }\end{array}$ & $\begin{array}{l}1900 \\
\text { Fixed } \\
2500\end{array}$ & at: & Fixed at: 10 & Fixed at: 4 \\
\hline & 3 & Fixed at: 155 & Fixed at: 150 & & $\begin{array}{l}\text { Fixed } \\
2600\end{array}$ & at: & Fixed at: 15 & Fixed at: 5 \\
\hline & 1 & Fixed at: 140 & Fixed at: 90 & Fixed at: 35 & Value & & Fixed at: 7 & Fixed at: 3 \\
\hline \multirow{2}{*}{ D } & 2 & Fixed at: 150 & Fixed at: 115 & Fixed at: 250 & increased & & Fixed at: 10 & Fixed at: 4 \\
\hline & 3 & Fixed at: 155 & Fixed at: 150 & Fixed at: 500 & $\begin{array}{l}{\left[\begin{array}{l}1900 \\
2600\end{array}\right]}\end{array}$ & to & Fixed at: 15 & Fixed at: 5 \\
\hline \multirow[t]{3}{*}{$\mathbf{E}$} & 1 & Fixed at: 140 & Fixed at: 90 & Fixed at: 35 & $\begin{array}{l}\text { Fixed } \\
1900\end{array}$ & at: & Value & Fixed at: 3 \\
\hline & 2 & Fixed at: 150 & Fixed at: 115 & Fixed at: 250 & $\begin{array}{l}\text { Fixed } \\
2500\end{array}$ & at: & $\begin{array}{l}\text { increased } \\
\text { [ } 7 \text { to } 15]\end{array}$ & Fixed at: 4 \\
\hline & 3 & Fixed at: 155 & Fixed at: 150 & Fixed at: 500 & $\begin{array}{l}\text { Fixed } \\
2600\end{array}$ & at: & & Fixed at: 5 \\
\hline \multirow[t]{3}{*}{$\mathbf{F}$} & 1 & Fixed at: 140 & Fixed at: 90 & Fixed at: 35 & $\begin{array}{l}\text { Fixed } \\
1900\end{array}$ & at: & Fixed at: 7 & \multirow{3}{*}{$\begin{array}{l}\text { Value } \\
\text { increased } \\
\text { [ } 3 \text { to 5] }\end{array}$} \\
\hline & 2 & Fixed at: 150 & Fixed at: 115 & Fixed at: 250 & $\begin{array}{l}\text { Fixed } \\
2500\end{array}$ & at: & Fixed at: 10 & \\
\hline & 3 & Fixed at: 155 & Fixed at: 150 & Fixed at: 500 & $\begin{array}{l}\text { Fixed } \\
2600\end{array}$ & at: & Fixed at: 15 & \\
\hline
\end{tabular}

Note: Condition or situation 1 is for the minimum parameter value, 2 for average parameter value and 3 for maximum parameter value

Figure 3-8 depict the result of the sensitivity analysis for all the six tests in controlled experiments. The graphs present the influence of the controlled experiments under varying conditions on the values of the Torque. Figure 3 depicts the result of test A, in which the Mixing temperature was increased from140 to 155 at minimum, average and maximum (situation 1, 2, \& 3) values and all other variables at fixed values, respectively. The value of Torque slightly dropped from 21 to less than $20 \mathrm{KNm}$ in condition 1 ; from 17 to $16 \mathrm{KNm}$ in condition 2; and 11.8 to $11 \mathrm{KNm}$ in condition 3 . In test $\mathrm{B}$ when the compaction temperature was increased from 90 to 150 , the value of Torque dropped from 21 to $15 \mathrm{KNm}$ in condition $1 ; 19$ to $13 \mathrm{KNm}$ in condition 2 and 17 to $11 \mathrm{KNm}$ in condition 3. In test $\mathrm{C}$ when Gyration was increased 35 to 500 for minimum, average and maximum values, value of Torques increase from 18 to $21 \mathrm{KNm}$ in condition $1 ; 15$ to $17 \mathrm{KNm}$ in condition 2 and 12 to $14 \mathrm{KNmin}$ condition 3. The findings imply that increase in Gyration will result to increase in the value of Torque. This is due to the low compaction temperature at high Gyration. This finding is consistent with Cardone et al. [19] who also used Gyratory Compactor in their research. Contrary to Bahia \& Hanson [20]; Huner \& Brown [21]; and Gudimettla et al. [6], who conclude that Gyratory compactor is not sensitive to temperature; this research finds that Gyratory compactor is sensitive to temperature. This difference can be largely attributed to effect of temperature on viscosity of mixture. Test $\mathrm{E}$ which was increased from 7 to 15 illustrated a slight drop in the values of the torque. In condition $1,21 \mathrm{KNm}$ dropped to $19 \mathrm{KNm} ; 17 \mathrm{KNm}$ to 14 in condition 2; and 13.5 to 
11 in condition 3. Conversely, Test F yielded slight increase in values of Torque when Flow was increased from 3 minimum and 5 maximum. The value of torque rose from 20 to $21 \mathrm{KNm} ; 16$ to $18 \mathrm{KNm}$ and 11 to $13 \mathrm{KNm}$, respectively.

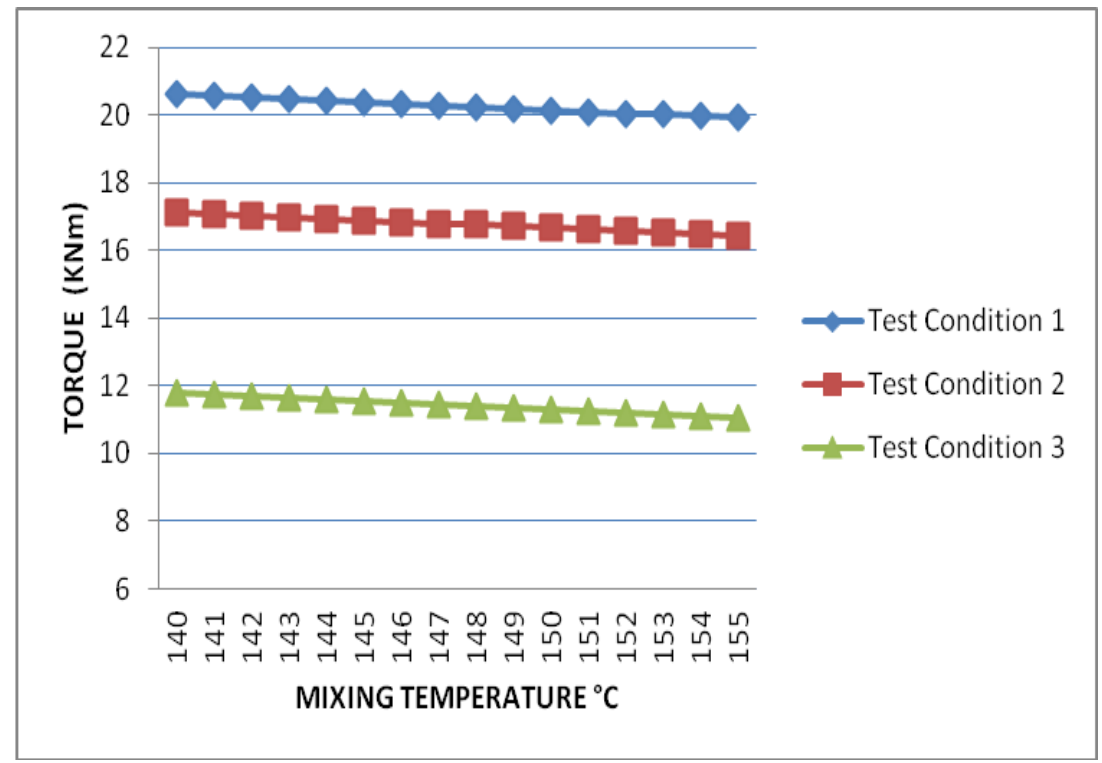

Fig. 3: Test A: effect of mixing temperature on Torque

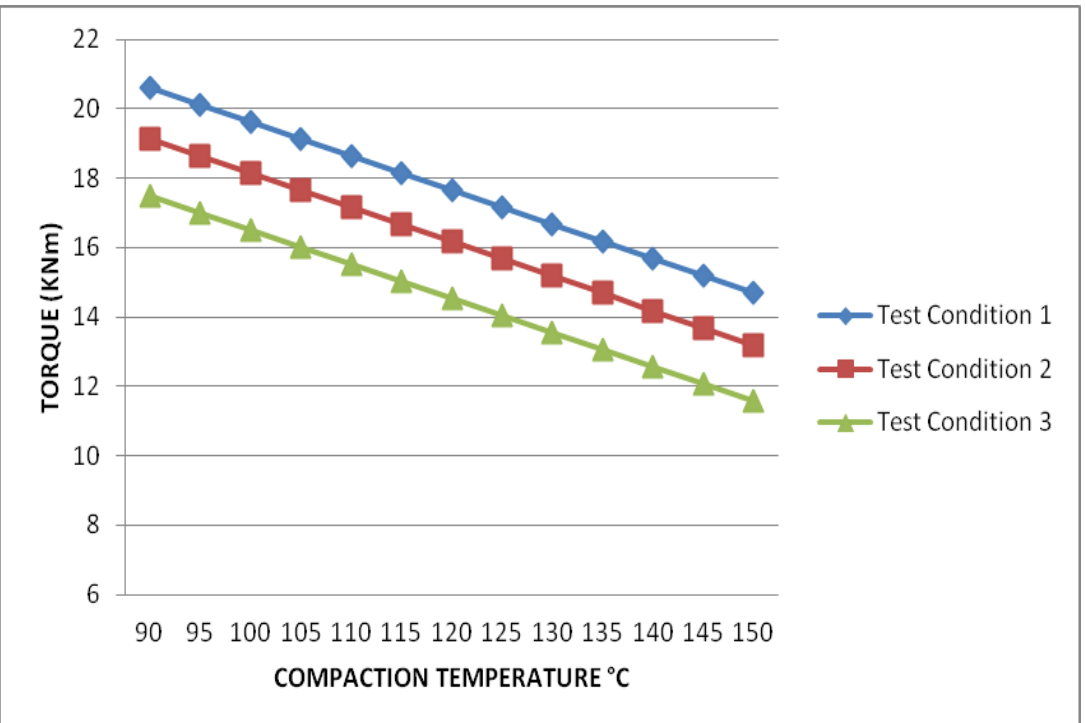

Fig. 4: Test B: effect of compaction temperature on Torque 


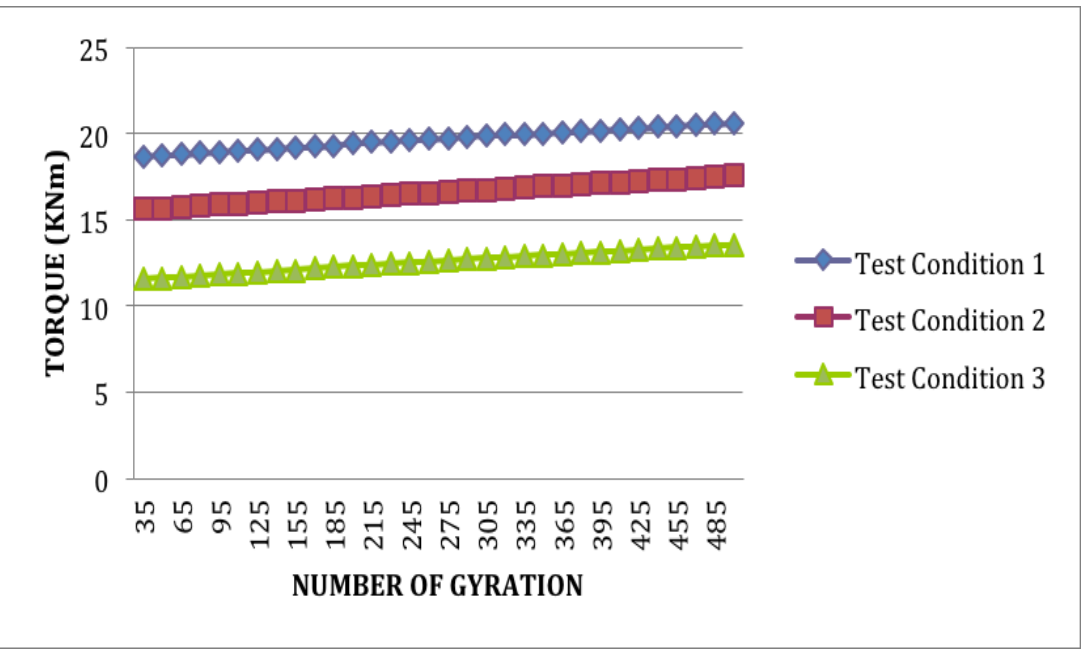

Fig. 5: Test C: effect of Gyration on Torque

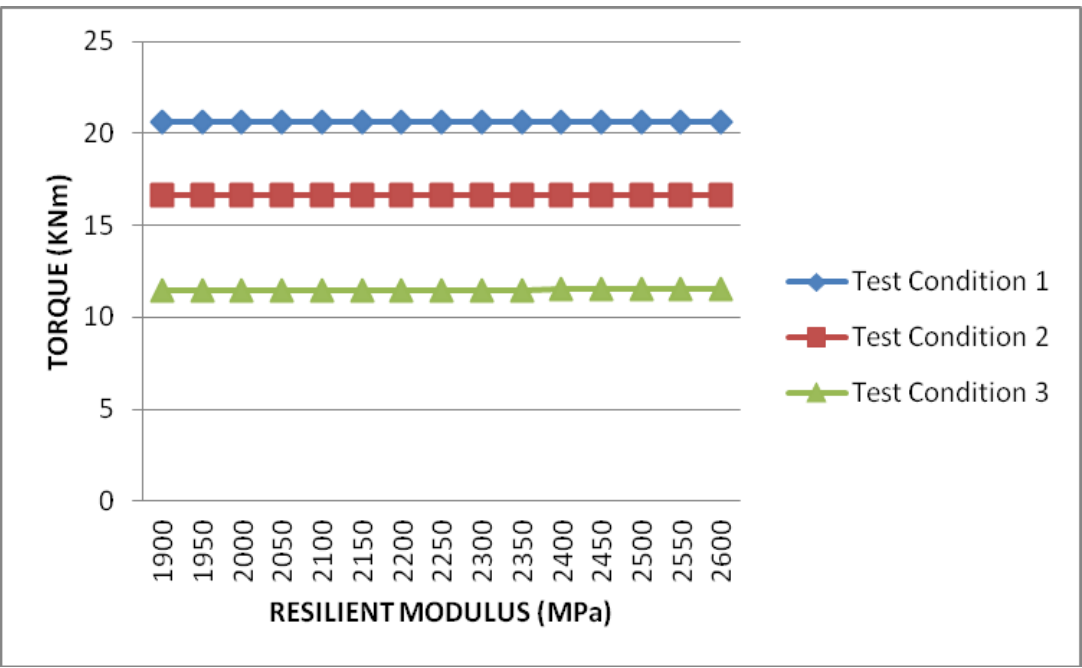

Fig. 6: Test D: effect of Resilient Modulus on Torque

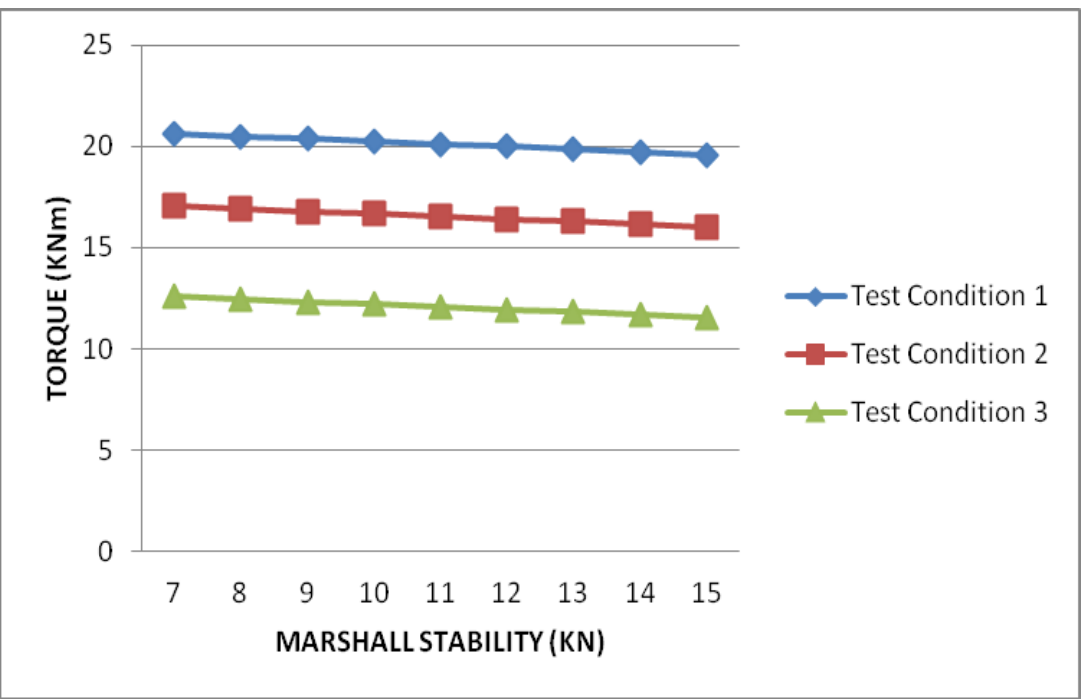

Fig. 7: Test E: effect of Marshall Stability on Torque 


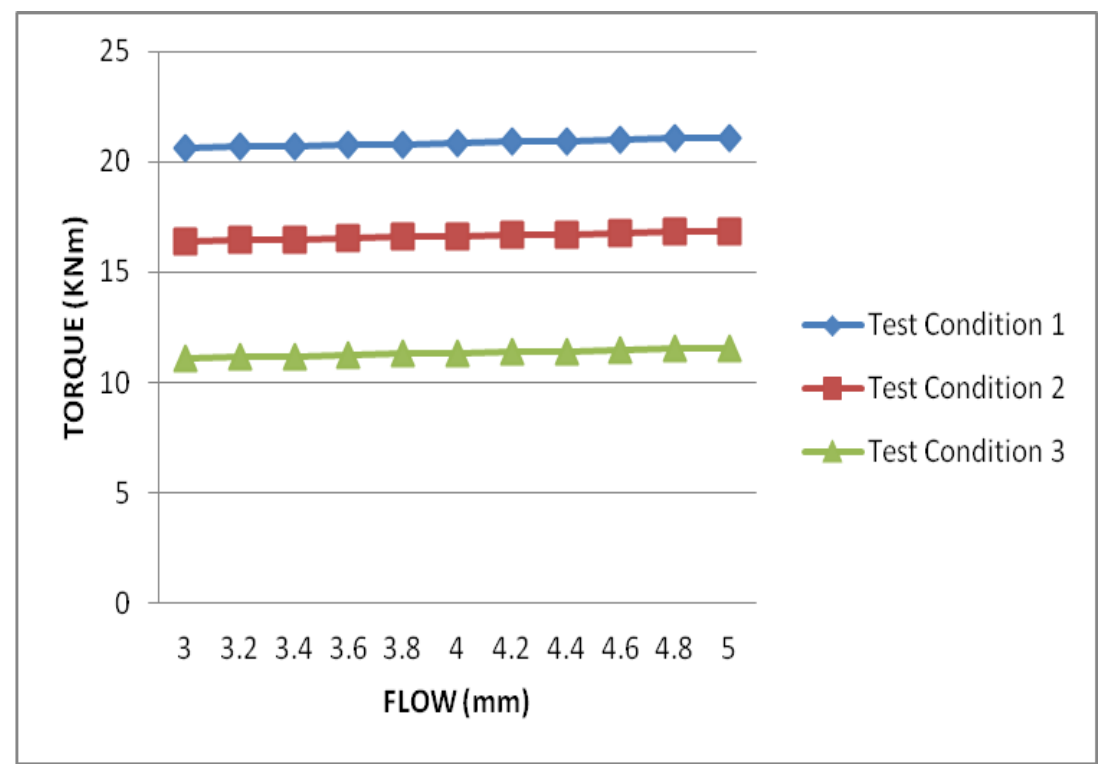

Fig. 8: Test F: effect of Flow on Torque

\section{Summary and conclusion}

This paper presents the statistical relationships between the Workability in Torque (dependent variable) and mixing temperature, Compaction temperature, Gyration, Resilient Modulus, Stability and Flow (independent variables). To determine the relationship, regression and sensitivity analyses were performed on the data obtained from the tests. Based on the results of the experiments and the analyses, the following conclusion can be drawn.

- As a whole, compaction is the strongest determinant of Torque.

- The value of Torque is influenced by Compaction, Mixing temperature and Gyration.

- There is no significant relationship between Torque; Resilient Modulus, Stability and Flow.

- The value of Torque drops when the mixing temperature increases and Compacting Temperature, Gyration, Resilient Modulus, Stability and Flow are controlled. Similar results are produced for Compacting temperature, Gyration, Resilient Modulus Stability with the exception of Flow, which results in an increase in the value of Torque.

\section{References}

[1] O.N. Celik and C.D. Atis, "Compactibility of hot bituminous mixtures made with crumb rubber-modified binders", Construction and Building Materials, 22, (2004), 1143-1147.

[2] K.A.J. Khweir, "The Influence of Material Ingredients on Asphalt Workability", (Unpublished Ph.D Thesis) Heriot-Watt University, Edinburgh, UK, 1991.

[3] H.K. Zubeck, L. Raad, S. Saboundjian, G. Minassian, and P.E. J. Ryer, "Workability and Performance of Polymer-modified Asphalt Aggregate Mixtures in Cold Regions", International Journal of Pavement Engineering, 4, 1, (2003), 25- 36.

[4] J. Marvillet, and P. Bougault, "Workability of bituminous mixes: Development of a workability meter" Proceedings of the Association of Asphalt Paving Technologists, 48, (1979), 91-110.

[5] J.M. Gudimettla, L.A. Jr. Cooley, and E.R. Brown, Workability of Hot Mix Asphalt. National Center for Asphalts Technology, NCAT Report 03-03, Auburn University, AL, USA, 2003.

[6] J.M. Gudimettla, L.A. Jr. Cooley and E.R. Brown, "Workability of Hot-Mix Asphalt", Transportation Research Record, 1891, (2004), 229237.

[7] J.G. Cabrera, "Assessment of the Workability of Bituminous Mixtures", Journal of Highways and Transportation, University of Leeds, 11, (1991), 17-23.

[8] J.G. Cabrera, Hot bituminous mixtures: Design for performance, "Proceedings of the 1st National Conference on Bituminous Mixtures and Flexible Pavements", University of Thessaloniki, Greece, (1992), 1-12. 
[9] J.G. Cabrera, Hot Bituminious Mixture Design for Performance, In J. G. Cabrera \& J. R. Dixon (Eds.), Performance and Durability of Bituminious Materials (1st ed., pp. 101-113). London: E \& FN SPON, 1996.

[10] A.A Mohamed, M.O. Hamzah and H. Omar, "Performance related mix design evaluation of asphaltic concrete", EASTS International Symposium on Sustainable Transportation incorporating Malaysian Universities Transport Research Forum Conference (MUTRFC08). Universiti Teknologi Malaysia, 12-13 August, (2008), 1-9.

[11] S.M. Khalil, A.K. Arshad and M.Y. Abdul Rahman, "The Development of Workability Measurement for Asphalt Mixture Using Transducer by Torque”, Int. J. Pavement Res. Technol, 5 (3), (2012), 203-208.

[12] PWD Malaysia, Standard Specification for Road Works, Section 4, Flexible Pavement. Jabatan. Kerja Raya Malaysia, Kuala Lumpur, 2008.

[13] BS 812 Part (105, 107, 112), Standard Method of Aggregate Testing, British Standard Institute (BSI) London, 1989.

[14] BS 812 Part $(105,107,112)$, Standard Method of Aggregate Testing, British Standard Institute (BSI) London, 1990

[15] BS 812 Part (105, 107, 112), Standard Method of Aggregate Testing, British Standard Institute (BSI) London, 1995

[16] American Society for Testing and Materials, Standard Test Method Standard, "Test Designation C 131, ASTM D 5; ASTM D 36; ASTM D 113, ASTM D 1559”, Annual Book of ASTM Standards (Section 04), West Conshohocken, Philadelphia, SA, 2004.

[17] D. Soper, Statistics Calculators. Retrieved February 2012, from http://danielsoper.com/statcalc3/default.aspx.

[18] NIST/SEMATECH, "e-Handbook of Statistical Methods" retrieved in March, (2012). http://www.itl.nist.gov/div898/handbook/

[19] V. Cardone, P.A. Virgili, P. A., \& S. Barbati, S, An evaluation of use of synthetic waxes in warm mix asphalt. In M. N. P. Andreas Loizos, Tom Scarpas, Imad L. Al-Qadi (Ed.), Advanced Testing and Characterization of Bituminous Materials, . London, UK: Taylor \& Francis Group, 2009.

[20] H.U. Bahia \& D.I. Hanson, Superpave Protocols for Modified Asphalt Binders Draft Topical Report (Task 9), Prepared for National Cooperative Highway Research Program,Transportation Research Board, National Research Council, 2000

[21] M.H. Huner, \& E.R. Brown, Effect of re-heating and compaction temperature on hot mix asphalt volumetric. Auburn, Ala: National Center for Asphalt Technology, 2001. 